This is an author accepted manuscript of the book chapter

Chapter title: Energy Efficiency Choices and Residential Sector: Observable Behaviors and Valuation Models Chapter authors: Marta Botero, Marina Bravi, Federico Dell'Anna, Carlos Marmolejo-Duarte

included in the book:

Mondini, G. et al. [eds]. Values and Functions for Future Cities. Cham, Switzerland: Springer Nature, 2020. ISBN 9783-030-23786-8. https://doi.org/10.1007/978-3-030-23786-8

The final authenticated version is available online at: https://doi.org/10.1007/978-3-030-23786-8_9 


\title{
ENERGY EFFICIENCY CHOICES AND RESIDENTIAL SECTOR: OBSERVABLE BEHAVIORS AND VALUATION MODELS
}

\author{
Marta Bottero, Marina Bravi, Federico Dell'Anna, Carlos Marmolejo-Duarte
}

\begin{abstract}
Over the last decade, households' preferences about energy efficiency measures in the residential sector have been the focus of a growing research employing models based on revealed and stated preferences. Analysis of households' energy consumption and demand elasticities were carry out before with the intent to forecast the potential of energy efficiency programs, but the recent concerns about climate change has drawn attention on the causes of this problem. As a result, the residential and renewable energy sectors have become strategic for the human being's future. Different retrofit measures and technical solutions are now available for the new buildings, but the existing residential stock is more difficult to improve. More specifically, this implies the investment decision of heterogeneous groups of homeowners and landlords who differ with respect to the characteristics of their assets, their financial possibilities and time preferences. Valuation models have helped to forecast the demand of both market and public goods. Based on different approaches and theories, these applications have opened new avenues of research, but leaving some questions unanswered. This work tries to take stock of a debate that is still open by comparing experiments based on revealed and stated preferences in this specific field.
\end{abstract}

\section{Introduction}

Measures implemented to improve energy efficiency are now recognized as a means of reducing greenhouse gas emissions, improving the procurement security, cutting down import costs, and creating a system less exposed to risks and volatility that global economic growth inevitably causes. In this direction, the real estate assets play a fundamental role, involving different economic sectors, from raw materials and technical installations to goods and services related to domestic supplies. Furthermore, facing the key challenge of fighting climate change while increasing the energy sector sustainability and maintaining economic growth will not be achieved without buildings energy efficiency. After all, the virtual supply of energy 
saved from a higher level of efficiency could generate multiple benefits to governments, businesses, and households, providing at the same time a market opportunity for a wide range of sectors.

Despite this trend, the immaterial nature of energy and its interweaving with everyday life make it difficult to observe and interpret, with the necessary scientific strictness, family choices and individual behaviors that are closely related to the sector. In this direction, the work intends to propose a reflection, also starting from previous experiments (Marmolejo-Duarte \& Bravi 2017; Becchio et al. 2019), on the possibilities of observing - and evaluating - households' choices related to energy saving, taking into account the role that a correct information plays in determining them. Although a reasonably large literature surveys various potential market failure in energy efficiency investment (Allcott \& Greenstone 2012; Gerarden et al. 2015), few efforts have been directed specifically on information programs. In fact, the intangible resources of communication appear to be an essential item to make the material resource of the energy works better and determining individual choices that are consistent to the social well-being.

Furthermore, the analysis of user behavior directly involved in relevant public policies - such as energy policy - has recently attracted the attention of scholars and policy-makers (Sousa Lourenço et al., 2016). It has been recognized that the increase in competition does not always offer an effective advantage to the consumers. Often, individual choices rely on a limited number of heuristics that, sometimes lead to reasonable judgments, and sometimes involve severe and systematic errors generating contradictory behaviors (Kahneman \& Tversky, 1984; Gilovich et al., 2001; Peon et al., 2017).

How can valuation approaches to individual choices take this matter into account? How can these experiments be used profitably, also in order to limit the buildings energy consumption? This work aims to answer these questions by proposing a reasoning about approaches based on revealed and stated preferences. For this purpose, in Section 2 the problem of energy consumption and families' choices related to the residential sector is analyzed, especially from the market - revealed preferences - point of view. Instead, Section 3 shows how a choice experiment could be employed to better understand the decision-making process and improve knowledge in this field; for this purpose, a brief summary of the relevant literature is recalled. Conclusions follow.

\section{Energy efficiency choices starting from revealed preferences analysis}

Changes from traditional energy production systems to low carbon technologies implies a shift in investments and not necessarily an increase in them, as well as a change in market dynamics. The reduction of greenhouse gas emissions does not imply horizontal cuts in spending as the different role that each socio-economic 
sector can play in the process of changing is recognized. The residential and tertiary sectors are those from which to expect, in the short term, the best results in terms of energy savings. Particularly, the interventions on the existing building stock appear to be strategic from this point of view.

The European Union has set some important principles on the buildings energy efficiency (GU, 2010, L 153/13) with the Energy Performance of Building Directive recast (EPBD recast). However, the lack of a common definition and evaluation of NZEBs (Nearly Zero Energy Building) by Member States has caused some difficulties and has slowed down the process of efficiency and energy savings. This led, recently, to the revision of the EPBD (European Commission, 2016) emphasizing the urgent need to reduce greenhouse gas emissions by involving all sectors, including the residential one.

In fact, despite the constant increase in the renewable sources penetration, it is necessary to reduce the amount of energy required to satisfy individuals and households consumption. The building stock consumes approx. $40 \%$ of gross primary energy, since it includes both the residential and services sectors. The European real estate assets are indeed old; most of the buildings were built before the implementation of the energy consumption standards and, in particular for the Mediterranean countries, the breakdown by construction period is as follows: $37 \%, 49 \%$ and $14 \%$, respectively for the period before 1960, between 1961 and 1990 and between 1991 and 2010 (BPIE, 2011). Therefore, the interventions on the existing stock are important because the newly buildings represent less than $1 \%$ per annum.

Given the urgency of stopping the anthropogenic environmental and energy impact, a substantial reform of a wide range of domestic energy behaviors is required in addition to other measures. In this perspective, consumers represent one of the main actors able to influence the energy transaction towards a post-carbon society (Fabi et al. 2017; Becchio et al. 2018). On the one hand, the adoption of measures disseminating sustainable energy sources and technologies, the installation of appliances bringing down the electric load as well as actions reducing the thermal demand through the building envelope efficiency, represent solutions purely related to new investments. On the other, the focus is shifting more and more towards the effects derived from the change in user behavior, with a lowered energy demand matching a supply coming from renewable sources. In this perspective, several kinds of research have been developed with the aim of investigating the factors that influence the public acceptability of energy policies (Steg et al. 2005), the adoption of renewable energy resources by the final users (Barthelmes et al. 2017), and the introduction of energy-efficient technologies in the private sector. It seems that inclusion in decision making leads individuals and families to more easily accept energy policies and changes in energy system, especially if their interests are taken into account (Perlaviciute \& Steg 2014). In this regard, it is necessary to clarify why there are still very low percentages of investments to improve energy efficiency.

The analysis of revealed preferences shows the presence of many barriers, including the investment size and the difficulty in forecasting the expected results. With regard to financial barriers, the amount of the investment is considered one of the 
main limitations to proceed, despite the economic return due to energy savings and the trend of rising in energy prices. The pay-back period is still another problem because, according to the single stakeholder, its acceptability could change. A substantial risk aversion to this kind of investment has also been demonstrated (Newell \& Sikamäki 2015). Besides, the choice to invest is faced to the competition with other types of goods bearing a status symbol and social prestige. In this direction, the perception and values that real estate assets represent make it difficult to generalize the policies goals. Tax incentives are not enough because they produce fragmentation of interventions, rather than achieving economies of scale with greater efficiency and effectiveness.

Moreover, energy expenditure implies a series of secondary phenomena, including split incentive, in which the investor is not the beneficiary of the intervention landlord $v s$. tenant or homeowner -, and rebound effect (Schleich et al. 2014), in which greater consumption offsets the energy saved by increasing efficiency. In this context, methods based on revealed preferences have not always been capable of entirely capturing user preferences by observing market behavior.

Many studies have tried to infer information on consumer preferences through the Hedonic Price Method (HPM), by observing real estate sales (Freeman et al. 2014). HPM is based on Lancaster's theory (1966) according to which people give value to a bundle of goods attributes. This approach allows to estimate costs and benefits associated to the structural and locational attributes that consumers believe are important when they buy a home. In light of this, a family maximizes its utility by simultaneously moving along each marginal price schedule, where this last can be interpreted as a household's willingness to pay for a unit of each attribute. HPM is generally used for environmental valuation purposes - parks and different kind of amenities - but, in recent years, a flourishing literature on energy efficiency demand has been developed. For example, since 2008, Member States have been obliged by the European Union to indicate for each building, built, sold or rented, the Energy Performance Certificate (EPC) that describes the energy performance. Many studies have shown that buildings with high energy performance level are appreciated compared to the others (Bottero et al. 2018; Bonifaci \& Copiello, 2015). Although, other have found a null impact of EPC rankings on prices (Olaussen et al., 2017; Fregonara et al. 2017) or only limited to some market segments (Marmolejo \& Chen, 2019). This latter finding interestingly coincide with opinion-based research, that have found that EPC rankings have a negligible impact on the housing market (Pascuas et al., 2017).

According to some studies, energy label appears to have achieved significant savings by inducing energy efficiency and increasing information transparency (Webber et al. 2000; Howarth et al. 2000). Furthermore, the results suggest as other incentives - such as green loans, subsidies and tax reductions - can promote energy savings encouraging real estate developers to offer building characterized by advanced green features (Gillingham et al., 2009). 


\section{Stated preferences and energy efficiency: how does a choice ex- periment could be modeled?}

Since human choice processes have been analyzed by different disciplines, there is not a unique theoretical framework to refer to. Ben-Akiva et al. (2002) depicted the state of the art of Predictive Choice Experiments (PCE) in relation to the more general field of human behavior analysis and they showed the differences, but also the fruitful exchanges occurred between the two. In fact, the research goals are different - prevision and regularity vs. deconstruction and heterogeneity - but this does not mean that various methodologies could not work together for the solution of empirical problems. The common objective is still today the individual choice process modelling in a variety of situations and applications.

As widely recognized, in the PCE, the Random Utility Maximization (RUM) model is the main referring framework. From the narrowest formulation (Marschak 1960; McFadden 1974; 2001) until today, the evolution of this theory has taken advantage from a progressive hybridization, so much to identify another generation of models with a new label, that of Hybrid Choice Models (HCB). The latter have tried to solve many issues arising from the experimentation: a) presence of heterogeneity across decision-makers due to different attitudes and perceptions (Greene et al. 2006); b) choice state-dependence (Viscusi \& Huber 2011); c) latent constructs and cognitive biases (Henscher \& Greene 2010) d) information processing (Denstadli et al. 2012); e) time preferences in presence of risk and uncertainty (Glenk \& Colombo 2013; Lundhede et. al. 2015).

For the reasons explained before, it is particularly interesting to focus on information availability in the consumer choice process, first of all by comparing real and hypothetical markets. Some aspects of this problem are often confused. For example, one would be led to believe that, while in a real markets information is transparent and accessible, in a simulated one - as in a choice experiment - de facto this cannot be. On the contrary, it has been widely demonstrated that consumers adapt the decision-making process to the available quantity of information each time they make a choice, real or hypothetical (Payne et al. 1993; Lacetera et al. 2014). From this perspective, potential sources of behavioral biases could cause: unobserved costs or overstated benefits, ignored product attributes or use of inappropriate discount rates in presence of risk and uncertainty.

Especially when the decision involves time preferences, the available information becomes a strategic item. Moreover, the profitability of energy efficiency investments depends fundamentally on the rate at which individuals discount future energy savings related to the initial investment; but individual discount rates exhibit considerable heterogeneity in experimental studies with time preferences elicitation (Newell \& Siikamäki 2015). In this sense, product or service choices may not minimize present value costs. Gerarden et al. (2015) outline that consumers may be inattentive to energy costs when purchasing products, but such lack of attention is not necessarily irrational. Bounded rationality could inhibit from properly balancing 
benefits and costs when comparing products or services where energy consuming is involved.

Furthermore, information availability is directly related to the selection bias; in other words, due to human limited attention, memory and processing capacities, individuals make decisions based on subsets of information that are easily and immediately available (Peon et al. 2017). This behavior determines an important collateral effect that has been tested in the PCE: the regret effect. An individual think «I would not want to regret not choosing or done... something», rather than maximizing the expected utility. Coherently, regret is defined as what one experiences when a non-chosen alternative performs better than a chosen one, taking in account one or more attributes. Boeri \& Longo (2017) show that Random Regret Minimization (RRM) model explains the respondents' choices better than RUM, indicating that regret is an important choice paradigm for renewable energy programmes. In other words, the Authors suggest that bounded rationality leads individuals to choose options that minimize their possible losses when considering energy saving.

\subsection{Modelling choice experiments}

In this Section a more specific comparison of choice experiments in the field of buildings energy efficiency is recalled with the intent to clarify how some of the issues referred to above could be managed. One of the first experiment in this sector was probably that of Cameron (1985) who employed data collected by a national survey on energy consumption. Analysis of households' energy consumption and demand elasticities were carry out also before to forecast the potential of energy efficiency programs (Li \& Just, 2018), but Cameron took on a choice model showing the demand sensitivity to changes in investment costs, energy prices and income.

A significant increasing of the relevant literature occurs only in the first decade of the 2000s, when greenhouse effect on environment and climate becomes more evident. Scholars probably consider the valuation models based on stated preferences more manageable, flexible and suitable for describing consumers hypothetical choices. Sadler's work (2003) is often cited as a good example of these first studies; she conducted two choice experiments among more than 600 owners of single family homes across Canada. In one of the two, respondents were asked to choose between a renovation that do not include energy efficiency retrofits and one that do it with only two alternatives with three attributes and two levels each. The results show that energy-efficient renovations are preferred compared to those without energy retrofits. Later, Banfi et al. (2008) use a choice experiment to evaluate the willingness to pay for energy-saving measures in Switzerland's residential buildings. These interventions include ventilation system and insulation of windows and facades; also in this case, the results suggest that the benefits of energy saving attributes are significantly considered by the consumers. While showing that a preference for this kind of investment does matter, these early applications do not go much further; the models employed are basically standard, like the Multinomial 
Logit Model (MLM) with fixed effects. Other possibilities will be experimented more later.

Kwak et al. (2010) estimate the willingness to pay for air-conditioning and heating considering three main attributes: windows, facade, and ventilation. More specifically, they test the hypothesis that energy efficiency choices would be nested. The Nested Logit Model (NLM) relaxes the so-called IIA (Independence of Irrelevant Alternatives) assumption - also known as binary independence - organizing the alternatives into groups and allowing for correlations among them. A little later, Achtnicht (2011) conducts a choice experiment concerning energy retrofits for existing houses in Germany; the respondents have to choose between a modern heating system or an improved thermal insulation for their home. In this case, a Mixed Logit Model is employed and the investment payback period is included, but removing the related uncertainty. Rouvinen \& Matero (2013) examine how different attributes of heating systems affect homeowners' choice following renovations when preferences heterogeneity is considered; a Random Parameters Logit (RPL) model allows to relax the IIA assumption identifying the random characteristics and taking under control consumers heterogeneity. Similarly, Becchio et al. (2019) opt for a RPL model to estimate the residents' willingness to pay for buildings energy retrofit of an urban district in Italy. By aggregating costs and willingness to pay for the entire district, the presence of a potential for improving the energy efficiency is verified with a variation related to the kind of investment: windows substitution or facades insulation.

More specifically and about information availability in households' decisionmaking, a large number of experiments cannot be found in this field. A certain attention is concentrated on the attributes selection process and the choice sets creation as well as the inclusion of information related to the greenhouse effect and the consequences of fossil energies consumption in general. Less work has been devoted to verifying the presence or absence of eventual biases able to influence the individual behavior. For example, Philips (2012) presents the results of a choice experiment used to investigate the preferences of landlords and tenants for insulation and heating retrofit in New Zeland. The first are willing to pay more for a heating appliance than any other option; on the contrary, the second have a low willingness to pay for heating substitution and would prefer under-floor insulation. Accordingly, a poor information may be a reason why many landlords are not willing to pay market prices for energy efficiency upgrades. About that, Michelsen \& Madlener (2012) analyze the influence of the preferences for specific attributes of residential heating system on the homeowners' adoption decision in Germany. They found there are different drivers, especially from sociodemographic and spatial point of view. Particularly important is the difference between newly and existing buildings.

Some studies consider reasons and motivations that encourage homeowners to carry out building energy retrofits as well as barriers against such investments. For example, Achtnicht \& Madlener (2014) directly investigate the reasons for and against building energy retrofits in Germany, but also apply a choice experiment 
involving different measures. Even though the most homeowners wait until single building elements are approaching the end of their useful life, before considering options for renovation or replacement, it seems they consider whether or not the additional costs for energy efficiency retrofit is affordable and profitable. Besides, the incentive effect of expert recommendations appears to be significant.

More recently, some Authors have outlined that the decision to retrofit should go beyond mere cost-benefit considerations and include other aspects as, for example, increase in indoor comfort. By means of a choice experiment, different thermal energy-saving measures in residential buildings has been investigated taking in account the individuals' environmental concerns (Galassi \& Madlener 2017). This last seems to be important in explaining consumers' heterogeneity. That the concerns about the environment and climate change are increasing in public opinion is however a fact (Alberini et al. 2018), and today the demand for transparent information about costs and benefits of energy saving measures could require urgent answers.

\section{Conclusions}

Buildings energy efficiency is clearly a strategic sector to mitigate the climate change effects that are becoming devastating and irreversible. In the last decades, Scholars have given a large contribution to the knowledge of consumers' behavior, also in uncertain conditions as those characterizing the energy consumption. It was demonstrated that information availability and environmental concerns are important to drive families' investment decision towards more efficient products. At the same time, the existent real estate assets need stronger and aimed policies able to overcome the fragmentation of single private initiatives.

The state of the art of revealed and stated preferences analysis in this specific field shows research advancing but also the incapacity to translate findings in practical advice for the policy-makers. Besides, econometric models based on inferential analysis bring with them the problem of the validity of the results under sampling conditions. And as it has been demonstrated by Olaussen et al. (2017) energy efficiency attributes can incorrectly absorb the impact produced over prices by other unobserved variables such as the architectonic quality, producing a spurious correlation between such performance and prices.

Usually, with stated preferences, respondents sampling requires more effort and resources, in front of smaller samples, than revealed preferences. These last are investigated through more extensive surveys, generally at the national level. What should probably be tested is the possibility of integrating directly observable consumer behavior with choice experiments. This has already been attempted but not in this specific sector. For example, the analysis of the investment choices already made by the families could identify their status quo and allow, through an interview based on a choice experiment, to keep heterogeneity under control. As well as panel data could help to understand how it is possible to increase sensitivity and sustainable behavior in energy consumption. 
(FRASE DI CHIUSURA O ALTRE CONSIDERAZIONI. POTETE AIUTARMI?)

\section{References}

Achtnicht M. (2011) Do Environmental Benefits Matter? Evidence from A Choice Experiment Among House Owners in Germany. Ecological Economics 70:21912200.

Alberini A, Bigano A, Ščasný M, Zvěřinová I. (2018) Preferences for Energy Efficiency vs. Renewables: What Is the Willingness to Pay to Reduce CO2 Emissions? Ecological Economics 144:171-185.

Allcott H, Greenstone M (2012) Is There an Energy Efficiency Gap? Journal of Economic Perspectives 26(1): 3-28.

Banfi S, Farsi M, Filippini M, Jakob M (2008) Willingness To Pay For EnergySaving Measures In Residential Buildings, Energy Economics 30:503-516.

Barthelmes VM, Becchio C, Fabi V, Corgnati SP (2017). Occupant Behaviour Lifestyles and Effects on Building Energy Use: Investigation on High and Low Performing Building Features. Energy Procedia 140:93-101.

Becchio C, Bottero M, Bravi M, Cavana G, Corgnati S., Dell'Anna F (2019) Buildings Energy Retrofit: Preferences Valuation Through a Choice Experiment. GEAM - Geoingegneria Ambientale e Mineraria Forthcoming.

Becchio C, Bertoncini ., Boggi, ., Bottero, ., Corgnat, SP, Dell'Anna F. (2018) The Impact of Users' Lifestyle in Zero-Energy and Emission Buildings: An Application of Cost-Benefit Analysis. In: New Metropolitan Perspectives, Springer International Publishing, 123-131.

Ben-Akiva M, McFadden D, Train K, Walker J, Bhat C, Bierlaire M (2002) Hybrid Choice Models: Progress and Challenges. Marketing Letters 13(3): 163-175.

Boeri M, Longo A (2017) The Importance of Regret Minimization in the Choice for Renewable Energy Programmes: Evidence from a Discrete Choice Experiment. Energy Economics 63:253-260.

Bonifaci P, Copiello S (2015) Real Estate Market and Building Energy Performance: Data for A Mass Appraisal Approach. Data in Brief 5:1060-1065.

Bottero M, Bravi M, Dell'Anna F, Mondini G (2018). Valuing Buildings Energy Efficiency Through Hedonic Prices Method: Are Spatial Effects Relevant? Valori e Valutazioni 21:27-40.

BPIE (Buildings Performance Institute Europe) (2011) Europe's Buildings Under the Microscope: A Country-by-Country Review of the Energy Performance of Europe's Buildings. http://bpie.eu/publication/europes-buildings-under-the-microscope/. 
Cameron TA (1985) A Nested Logit Model for Energy Conservation Activity by Owners of Existing Single-Family Dwellings. The Review of Economics and Statistics 67(2): 205-211.

European Commission (2016) Accelerating Clean Energy in Buildings. COM 2016 860 final Annex 1.

Denstadli JM, Lines R, Ortuzar J (2010) Information Processing in Choice-Based Conjoint Experiments. A Process-Tracing Study. European Journal of Marketing 46(3-4): 422-445.

Fabi V, Di Nicol MV, Spigliantini G, Corgnati SP (2017) Insights on Pro-Environmental Behavior Towards Post-Carbon Society. Energy Procedia 134:462-469.

Freeman AM III, Herriges JA, Kling CL (2003) The Measurement of Environmental and Resource Values: Theory and Methods. Resources for the Future, Routledge, Washington DC.

Fregonara, E., Rolando, D., \& Semeraro, P. (2017). Energy Performance Certificates in the Turin real estate market. Journal of European Real Estate Research, 10(2), 149-169

Galassi V., Madlener R. (2017) The Role of Environmental Concern and Comfort Expectations in Energy Retrofit Decisions. Ecological Economics 141: 53-65.

Gerarden T, Newell RG, Stavins RN (2015) Deconstructing the Energy-Efficiency Gap: Conceptual Frameworks and Evidence. The American Economic Review 105(5): 183-186. 
Gillingham K, Newell R. G, Palmer K (2009). Energy Efficiency Economics and Policy. Discussion Paper RFF DP 09-13, Resource for the Future, Washington DC. Gilovich T, Griffin D, Kahneman D. (2002) Euristic and Biases: The Psychology of Intuitive Judgement. Cambridge University Press, Cambridge UK.

Glenk K, Colombo S (2013) Modelling Outcome-Related Risk in Choice Experiments. The Australian Journal of Agricultural Economics 57(4): 559-578.

Greene WH, Hensher DA, Rose J (2006) Accounting for Heterogeneity in the Variance of Unobserved Effects in Mixed Logit Model. Transportation Research 40B(1):75-92.

Hensher DA, Greene WH (2010) Non-Attendance and Dual Processing of Common-metric Attributes in Choice Analysis: A Latent Class Specification. Empirical Economics 39:413-426.

Howarth R, Haddad BM, Paton B (2000) The Economics of Energy Efficiency: Insights from Voluntary Participation Programs. Energy Policy 28(6-7):477-486.

Kahneman D, Tversky A (1984) Choices, Values and Frames. American Psychologist 39:341-350.

Kwak, S-Y, Yoo S-H, Kwak S-J, (2010) Valuing Energy-saving Measures in Residential Buildings: A Choice Experiment Study. Energy Policy 38(1): 673-677.

Lacetera, N, Pope DG, Sydnor JR (2014) Heuristic thinking and limited attention in the car market. The American Economic Review 102(5): 2206- 2236.

Li J, Just RE (2018) Modeling Household Energy Consumption and Adoption of Energy Efficient Technology. Energy Economics 72: 1-678.

Achtnicht M, Madlener R (2014) Factors Influencing German House Owners' Preferences On Energy Retrofits. Energy Policy 68:254-263.

Lundhede TH, Jacobsen JB, Hanley N, Strange N, Thorsen BJ (2015) Incorporating Outcome Uncertainty and Prior Outcome Beliefs in Stated Preferences. Land Economics 91(2): 296-316.

Marmolejo-Duarte C, Bravi M. (2017) Does the Energy Label (EL) Matter in the Residential Market? A Stated Preference Analysis in Barcelona, Buildings 7:53 https://www.mdpi.com/2075-5309/7/2/53.

Marmolejo-Duarte, C.; Chen, A. The Uneven Price Impact of Energy Efficiency Ratings on Housing Segments. Implications for Public Policy and Private Markets. Sustainability 2019, 11, 372 . 
Marschak, J. (1960) Binary Choice Constraints on Random Utility Indicators. In: Arrow K (eds) Stanford Symposium on Mathematical Methods In The Social Sciences. Stanford, CA: Stanford University Press, 312-29.

McFadden D (1974) Conditional Logit Analysis of Qualitative Choice Behavior. In: Paul Zarembka (eds) Frontiers in Econometrics. New York: Academic Press, 1974, 105-42.

McFadden D. (2001) Economic Choices, The American Economic Review 91(3): 351-378.

Michelsen CC, Madlener R (2012) Homeowners' Preferences for Adopting Innovative Residential Heating Systems: A Discrete Choice Analysis for Germany. Energy Economics 34: 1271-1283.

Newell RG, Siikamäki J (2015) Individual Time Preferences and Energy Efficiency. The American Economic Review 105(5):196-200.

Payne JW, Bettman JR, Johnson EJ (1993) The Adaptive Decision Maker. Cambridge University Press, New York, NY.

Olaussen, J.O.; Oust, A.; Solstad, J.T. Energy Performance Certificates_-Informing the Informed or the Indifferent? Energy Policy 2017, 111, 246-254

Pascuas, R.P.; Paoletti, G.; Lollini, R. Impact and Reliability of EPCs in The Real Estate Market. Energy Procedia 2017, 140, 102-114

Peón D, Antelo M, Calvo-Silvosa A. (2017) An Inclusive Taxonomy of Behavioral Biases. European Journal of Government and Economics 6(1): 24-58.

Perlaviciute G, Steg L. (2014). Contextual and Psychological Factors Shaping Evaluations and Acceptability of Energy Alternatives: Integrated Review and Research Agenda. Renewable and Sustainable Energy Reviews 35:361-381.

Phillips Y (2012) Landlords Versus Tenants: Information Asymmetry and Mismatched Preferences for Home Energy Efficiency. Energy Policy 45:112-121.

Rouvinen S, Matero J (2013) Stated Preferences of Finnish Private Homeowners For Residential Heating Systems: A Discrete Choice Experiment. Biomass and Bioenergy 57: 22-32.

Sadler M (2003) Home Energy Preferences and Policy: Applying Stated choice Modeling to a Hybrid Energy Economic Model. Report to Natural Resources Canada, Simon Fraser University.

Sousa Lourenço J, Ciriolo E, Rafael Almeida S, Troussard X (2016) Behavioural Insights Applied to Policy: European Report 2016. JRC EUR 27726 EN. 
https://publications.europa.eu/en/publication-detail/-/publication/eb1f5ea2-d3ae11e5-a4b5-01aa75ed71a1/language-en.

Schleich J, Mills B, Dütschke E. (2014) A Brighter Future? Quantifying to Rebound Effect in Energy Efficient Lighting. Energy Policy 72:35-42.

Steg, L, Perlaviciute G, van der Werff E (2015) Understanding the Human Dimensions of a Sustainable Energy Transition. Frontiers in Psychology 6. https://doi.org/10.3389/fpsyg.2015.00805.

Viscusi WK, Huber J (2012) Reference-dependent Valuations of Risk: Why Willingness-to-Accept Exceeds Willingness-to-Pay. Journal of Risk and Uncertainty 44(1):19-44.

Webber C, Brown R, Koomey J (2000). Savings Estimates for The Energy Star ${ }^{\circledR}$ Voluntary Labeling Program. Energy Policy 28(15):1137-1149. 